\title{
Biomarkers Related to Carotid Intima-Media Thickness and Plaques in Long-Term Survivors of Ischemic Stroke
}

\author{
Ulrike Waje-Andreassen $^{1} \cdot$ Halvor Naess $^{1} \cdot$ Lars Thomassen $^{1,2}$. \\ Tove Helene Maroy ${ }^{1}$ Kibret Yimer Mazengia ${ }^{1}$ - Geir Egil Eide ${ }^{3,4}$. \\ Christian Alexander Vedeler ${ }^{1,2}$
}

Received: 11 January 2015 /Revised: 28 March 2015 / Accepted: 28 April 2015 / Published online: 8 May 2015

(C) The Author(s) 2015. This article is published with open access at Springerlink.com

\begin{abstract}
Lifestyle risk factors, inflammation and genetics play a role in the development of atherosclerosis. We therefore studied Fc gamma receptor (Fc $\gamma \mathrm{R})$ polymorphisms, interleukin (IL)-10 polymorphisms and other biomarkers related to carotid intima-media thickness (cIMT) in patients with ischemic stroke at a young age. Patients were evaluated 12 years after stroke occurrence. Patients $(n=232) 49$ years of age or younger with an index stroke between 1988 and 1997 were retrospectively selected. Blood samples were taken at a first follow-up 6 years after the stroke. At a second follow-up, additional arterial events were registered for 140 patients, new blood samples were taken, and measurements of cIMT and blood pressure (BP) were performed. Unadjusted logistic regression analysis showed that $\mathrm{cIMT} \geq 1 \mathrm{~mm}$ was associated with age, male gender, additional arterial events, BP, cholesterol, sedimentation rate, haemoglobin, triglycerides, creatinine, glycolysed haemoglobin (HbAlc) and Fc $\gamma$ RIIIB-NaII/ NaII. Adjusted backward stepwise logistic regression showed significance for age (odds ratio (OR) 1.13, $95 \%$ confidence interval (CI) 1.04 to1.23, $p=0.003$ ), male gender (OR 4.07, $95 \%$ CI 1.15 to $14.5, p=0.030$ ), HbAlc (OR 6.65, $95 \%$ CI
\end{abstract}

Ulrike Waje-Andreassen

uwan@helse-bergen.no

1 Department of Neurology, Haukeland University Hospital, Jonas Lies vei 65, N-5021 Bergen, Norway

2 Department of Clinical Medicine, University of Bergen, Bergen, Norway

3 Centre for Clinical Research, Haukeland University Hospital, Bergen, Norway

4 Lifestyle Epidemiology Research Group, Department of Global Public Health and Primary Care, University of Bergen, Bergen, Norway
1.21 to 36.5, $p=0.029$ ) and FcyRIIIB-NaII/NaII (OR 3.94, $95 \%$ CI 1.08 to $14.3, p=0.037$ ). In this long-term follow-up study of patients with ischemic stroke at a young age, Fc $\gamma$ RIIIB-NaII/NaII was identified as a possible contributing factor for cIMT $\geq 1 \mathrm{~mm}$ together with known risk factors, such as age, male gender, systolic BP, additional arterial events and HbAlc.

Keywords Young ischemic stroke $\cdot$ Long-term follow-up · Carotid IMT $\cdot$ Fc gamma receptors $\cdot$ IL-10 $\cdot \mathrm{HbA1c}$

\section{Introduction}

Atherosclerosis is an inflammatory disease with both lifestyle and genetic risk factors. Receptors for the Fc portion of immunoglobulin $\mathrm{G}(\mathrm{IgG})$, known as Fc $\gamma \mathrm{Rs}$, are the binding link between humoral and cellular immunologic reactions. Endothelial cells express Fc $\gamma$ Rs and pro-inflammatory mediators, such as immune complexes and C-reactive protein, that can activate Fc $\gamma \mathrm{R}$-dependent pathways that lead to oxidative burst, degranulation, phagocytosis, cytokine production and antibody-dependent cell-mediated cytotoxicity (ADCC) [1]. The Fc $\gamma$ Rs are surface glycoproteins, encoded by eight genes located on chromosome 1q21-23. Based on structural homology and differences in affinity for $\operatorname{IgG}$, this family is divided into three subfamilies: Fc $\gamma$ RI (CD64), Fc $\gamma$ RII (CD32) and Fc $\gamma$ RIII (CD16). Fc $\gamma \mathrm{R}$ isoforms can be activating receptors (FcRI, Fc $\gamma$ RIIA and Fc $\gamma$ RIII) or inhibitory receptors (Fc $\gamma$ RIIB) [1]. Two studies have demonstrated associations between certain Fc $\gamma$ RIIA polymorphisms and coronary artery disease (CAD) and ischemic stroke [2,3]. However, a study of patients with myocardial infarction and patients with $\mathrm{CAD}$, documented by angiography, did not confirm this association [4]. Protective effects have been reported for the Fc $\gamma$ RIIA 
polymorphism and peripheral atherosclerosis [5], and an inverse relation has been found for Fc $\gamma$ RIIIA and CAD [6].

Interleukin (IL)-10 is another important immune regulator that may be important in the pathogenesis of atherosclerosis [7]. Low levels of expression of IL-10 are associated with atherosclerosis and cardiac and vascular dysfunction in mouse models [8,9], and in humans, reduced levels of IL-10 are associated with carotid atherosclerosis and coronary disease $[10,11]$. IL-10 production varies due to single-nucleotide polymorphisms (SNPs) in the promoter region of the IL-10 gene [12]. IL-10 SNPs have been identified at positions -1082 $(\mathrm{A} / \mathrm{G}),-819(\mathrm{C} / \mathrm{T})$ and $-592(\mathrm{~A} / \mathrm{C})$ in Caucasians and form the haplotypes ATA, ACC and GCC in six possible combinations [13]. The genotype GCC/GCC is associated with high production of IL-10; GCC/ACC and GCC/ATA with medium production; and ATA/ATA, ATA/ACC and ACC/ACC with low production of IL-10 [14]. Although the IL-10 gene is also localised on chromosome 1, the polymorphisms of IL-10 and $\mathrm{F} c \gamma \mathrm{R}$ are not related. However, it has been shown that crosslinking of Fc $\gamma$ Rs on macrophages influence the IL-10 production [15].

We have previously reported data from 232 patients who had suffered acute arterial ischemic stroke at ages between 15 and 49 years and found a 10 -fold higher mortality rate and a 5 fold increased vascular morbidity rate among long-term survivors compared with controls [16]. After a mean observation time of 12 years from the index stroke, individual maximum carotid intima-media thickness (cIMT) values were $\geq 1.0 \mathrm{~mm}$ in $76 \%$ of 140 examined patients, based on 5944 wallsegmental measurements [17].

In the present study, we analysed these retrospectively selected young stroke patients with the following biomarkers: C-reactive protein (CRP), homocysteine, cholesterol and triglycerides, sedimentation rate $(\mathrm{SR})$, haemoglobin $(\mathrm{Hb})$, glycolysed haemoglobin (HbA1c), creatinine, leukocytes, thrombocytes, and Fc $\gamma \mathrm{R}$ polymorphisms, IL-10 polymorphisms and Chlamydia pneumoniae antibodies. For multivariate analysis, we related these parameters and other relevant clinical information, such as age, gender, blood pressure, number of smoking years and additional arterial events other than the index stroke to cIMT.

\section{Methods}

\section{Patients and Study Design}

We identified 232 patients of less than 50 years of age with first-ever ischemic stroke between 1988 and 1997 from five acute care hospitals in Hordaland County in western Norway [16]. The mean age (standard deviation, SD) of the subjects was $41.1( \pm 7.5)$ years at the time of the index stroke. Ischemic stroke was defined according to the Baltimore Washington
Cooperative Young Stroke Study Criteria as neurological deficits lasting longer than $24 \mathrm{~h}$ or clinical transient ischemic attacks (TIAs) in which cerebral computed tomography (CT) or magnetic resonance imaging (MRI) showed acute arterial cerebral infarction related to clinical findings [18]. About two thirds of the patients had anterior circulation infarction, about one third had posterior circulation infarction, and despite more serious affection of patients with anterior circulation infarction, the short-term outcome at discharge was favourable with modified Rankin score $\leq 2$ in 80 \% [19]. From 1988 to 1997, patients were mainly treated by platelet inhibition or anticoagulation. Thrombolysis and treatment with statins were not usual at that time. Figure 1 shows the flow chart of the study. The first follow-up was done from 1998 to 2001 after a mean time of 5.7 years from the index stroke. Blood samples were taken from 198 participating patients and frozen at $-80{ }^{\circ} \mathrm{C}$. Four patients refused blood sampling. A second follow-up was done from 2004 to 2005 after a mean time of 11.9 years from the index stroke. Until the second follow-up, 45 patients had died, mainly from cardiovascular disease [20]. Of the 187 survivors, 144 (77\%) participated in clinical examinations, and 140 patients were examined with cIMT measurements by B-mode ultrasound [17]. Two patients refused blood sampling but permitted the use of samples taken for other control purposes within 1 month. The mean age at this follow-up was 52.9 years ( $\mathrm{SD} \pm 8.1$, range $28-65$ years).

\section{Fc $\gamma$ R Polymorphisms}

Fc $\gamma \mathrm{R}$ polymorphisms were analysed as previously described [6]. In brief, leukocytes were isolated from peripheral venous blood samples (EDTA blood). DNA was extracted with QIAampTM Blood Kit (Qiagen GmbH, Hilden, Germany). Fc $\gamma$ R genotypes were determined by polymerase chain reaction (PCR), and all PCR products were analysed by electrophoresis [6].

\section{IL-10 Polymorphisms}

DNA was extracted from whole-blood samples and examined for IL-10 polymorphisms at positions -1082 (G/A), -819 (T/C) and $-592(\mathrm{~A} / \mathrm{C})$ using PCR and gene sequencing as previously described [21]. The IL-10 haplotypes were determined and grouped into combinations with high IL-10 expression, medium IL-10 expression and low IL-10 expression.

\section{Carotid Artery Imaging}

Right- and left-sided cIMT examination of near and far walls of the distal common carotid artery (CCA), bifurcation (BIF) and the proximal internal carotid artery (ICA) were performed at four predefined angles. CCA, BIF and ICA vessel segments were identified by using the tip of the flow divider as an 


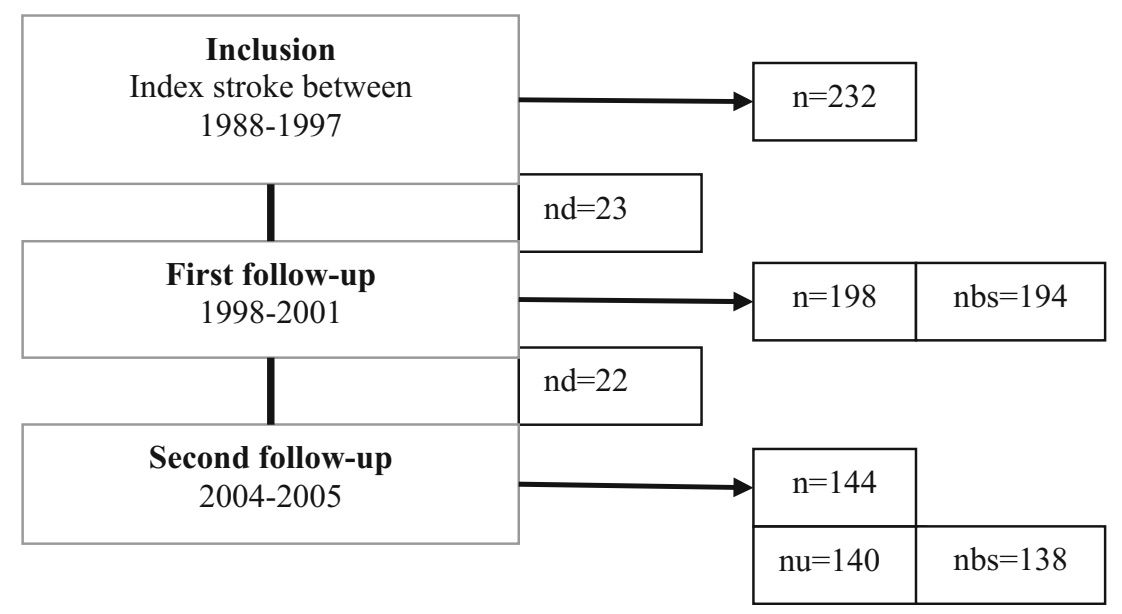

Fig. 1 Flow chart of 232 retrospectively included ischemic stroke patients after the index stroke at age 17 to 49 years; $n=$ number of patients who were identified and participated in follow-ups, $n d=$ numbers of patients who died between inclusion and first follow-up and between first and second follow-up, $n b s=$ number of collected blood

internal landmark. Segments had a length of $10 \mathrm{~mm}$, and the mean value was measured. A total of 5944 segmental mean IMT or plaque values were obtained. The maximum value of 48 possible individual cIMT measurements was used as outcome variable. cIMT results were used to divide subjects into two cIMT categories: $<1.0$ and $\geq 1.0 \mathrm{~mm}$. Our 140 patients had a mean age of 53 years, the oldest patients were 65 years old at that final clinical follow-up, and total maximum IMT of $1.0 \mathrm{~mm}$ was chosen as measure of dichotomisation due to literature [22, 23]. Methods, results and patients' characteristics were previously described in detail [17].

\section{Data Analysis}

Biomarkers were compared between the groups with cIMT $<1 \mathrm{~mm}$ and cIMT $\geq 1 \mathrm{~mm}$. Age, additional arterial events, systolic and diastolic BP, number of smoking years, SR, HbAlc, creatinine, Hb, leukocytes, thrombocytes and triglycerides were used as results from the second follow-up. CRP, homocysteine, total cholesterol, LDL cholesterol and HDL cholesterol were used as results from the first and second follow-up. Categorical variables were analysed with $3 \times 2$ chi-square test and Fisher's exact test, and Wilcoxon-Mann-Whitney test was used for continuous variables. Unadjusted logistic regression analysis of the dichotomised cIMT was used to evaluate the potential relationships with $\mathrm{Fc} \gamma \mathrm{R}$ polymorphisms, IL-10 haplotypes with ATA/ATA as reference variable and with C. pneumoniae antibodies. $p$ values were calculated from the likelihood ratio test. Multiple logistic regression analysis was done using the dichotomised cIMT results as outcome in a backward stepwise selection process retaining variables significant at the $5 \%$ level in the final model. Multiple linear regression analysis was done using samples. Four patients at first follow-up and two patients at second follow-up refused blood sampling, but both patients from second follow-up permitted the use of blood samples from other health controls, done within 1 month; $n u=$ number of patients with carotid ultrasound measurements

continuous maximum cIMT results as outcome in a backward stepwise selection process retaining variables significant at the $5 \%$ level in the final model. The analysis was performed using the Statistical Package for Social Sciences (SPSS) 20. $p$ values $<0.05$ were considered significant.

\section{Results}

\section{Immunological Parameters and cIMT}

Table 1 shows Fc $\gamma$ RIIIB polymorphisms associated with cIMT $\geq 1 \mathrm{~mm}$. Table 2 shows total cholesterol, LDL cholesterol and homocysteine from the first follow-up associated with cIMT $\geq 1 \mathrm{~mm}$, and further association with $\mathrm{Hb}$, $\mathrm{HbA} 1 \mathrm{c}$ and creatinine from the second follow-up. Age, gender, systolic and diastolic BP and additional arterial events were also associated with cIMT $\geq 1 \mathrm{~mm}$ (Table 2). We found a significant association between the Fc $\gamma$ RIIIB NAII/NAII polymorphism and cIMT $\geq 1 \mathrm{~mm}$ by using unadjusted logistic regression and adjusted backward stepwise logistic regression analysis (Table 3). However, linear regression analysis showed non-significant results for the Fc $\gamma$ RIIIB NAII/NAII polymorphism relation with continuous cIMT. There was also a significant association between the IL-10 GCC/ACC polymorphisms and cIMT $\geq 1 \mathrm{~mm}$, but this was not correlated with other polymorphisms associated with the degree of IL-10 production (Table 1). Therefore, we did not follow up the IL-10 results by performing final backward stepwise logistic and linear regression analysis. C. pneumoniae antibodies, sedimentation rate and $\mathrm{C}$-reactive protein were not associated with $\mathrm{cIMT} \geq 1 \mathrm{~mm}$. 
Table 1 Fc gamma receptor (Fc $\gamma \mathrm{R}$ ) polymorphisms and interleukin (IL)-10 polymorphisms related to carotid intima-media thickness (cIMT) with $\geq 1 \mathrm{~mm}$ as outcome variable

\begin{tabular}{|c|c|c|c|c|}
\hline Variables & $\begin{array}{l}\text { Number } \\
\%\end{array}$ & $\begin{array}{l}\text { cIMT }<1 \mathrm{~mm} \\
n=34\end{array}$ & $\begin{array}{l}\text { cIMT } \geq 1 \mathrm{~mm} \\
n=104\end{array}$ & $\begin{array}{l}\text { LR test } \\
p \text { value }\end{array}$ \\
\hline \multicolumn{5}{|l|}{$\mathrm{Fc}$ gamma receptor $(\mathrm{Fc} \gamma \mathrm{R})$ polymorphisms } \\
\hline Fc $\gamma$ RIIA & $n=138$ & & & 0.313 \\
\hline $\mathrm{H} / \mathrm{H}$ & 15.9 & 5 & 17 & \\
\hline $\mathrm{H} / \mathrm{R}$ & 42.0 & 18 & 40 & \\
\hline $\mathrm{R} / \mathrm{R}$ & 42.0 & 11 & 47 & \\
\hline Fc $\gamma$ RIIIB & $n=138$ & & & 0.036 \\
\hline $\mathrm{NaI} / \mathrm{NaI}$ & 12.0 & 6 & 10 & \\
\hline $\mathrm{NaI} / \mathrm{NaII}$ & 43.5 & 19 & 41 & \\
\hline $\mathrm{NaII} / \mathrm{NaII}$ & 44.9 & 9 & $53 *$ & \\
\hline Fc $\gamma$ RIIIA & $n=137$ & & & 0.362 \\
\hline$V / V$ & 12.4 & 2 & 15 & \\
\hline $\mathrm{V} / \mathrm{F}$ & 40.9 & 15 & 41 & \\
\hline $\mathrm{F} / \mathrm{F}$ & 46.7 & 17 & 47 & \\
\hline \multicolumn{5}{|l|}{ Interleukin (IL)-10 polymorphisms } \\
\hline & $n=138$ & & & 0.102 \\
\hline ATA/ATA & 7.2 & 4 & 6 & \\
\hline ATA/ACC & 9.4 & 5 & 8 & \\
\hline $\mathrm{ACC} / \mathrm{ACC}$ & 7.2 & 1 & 9 & \\
\hline $\mathrm{GCC} / \mathrm{ACC}$ & 26.8 & 4 & $33^{*}$ & \\
\hline GCC/ATA & 23.2 & 10 & 22 & \\
\hline $\mathrm{GCC} / \mathrm{GCC}$ & 26.1 & 10 & 26 & \\
\hline \multicolumn{5}{|l|}{ IL-10 producing genotypes [14] } \\
\hline $\begin{array}{l}\text { Low IL-10 production: } \\
\text { ATA/ATA, ATA/ACC and ACC/ACC }\end{array}$ & & 10 & 23 & 0.353 \\
\hline Medium IL-10 production: GCC/ACC and GCC/ATA & & 14 & 55 & 0.238 \\
\hline $\begin{array}{l}\text { High IL-10 production: } \\
\text { GCC/GCC }\end{array}$ & & 10 & 26 & 0.655 \\
\hline
\end{tabular}

$n$ number, $L R$ likelihood ratio test from logistic regression

* Significant $p$ value, $p \leq 0.05$

\section{Non-immunological Parameters and cIMT}

cIMT $\geq 1 \mathrm{~mm}$ was associated with total cholesterol, LDL cholesterol and homocysteine at the first, but not at the second, follow-up (Table 2). Haemoglobin, HbA1c and creatinine were also associated with cIMT $\geq 1 \mathrm{~mm}$ as were age, male gender, systolic and diastolic BP and additional arterial events other than the index stroke. HbAlc was associated with cIMT $\geq 1 \mathrm{~mm}$ in addition to age and male gender after unadjusted logistic regression and results after adjusted backward stepwise logistic regression analysis (Table 3 ). Final linear regression analysis for continuous cIMT showed associations with age, additional arterial events, systolic BP and $\mathrm{HbAlc}$ (Table 4). Male gender was no longer associated with cIMT in that analysis.

\section{Discussion}

This is the first clinical study of long-term survivors of ischemic stroke at a young age to evaluate follow-up blood samples and carotid IMT measurements. The mean observation time was nearly 12 years, and the cIMT measurements also included plaques, as we measured at standardised sites in order to perform a staging of the carotid artery wall disease.

We have studied immunological and non-immunological risk factors for cIMT as parameters for carotid atherosclerosis. Our results showed no association with $C$. pneumoniae antibodies and cIMT. The association between $C$. pneumoniae antibodies and cardiovascular disease is unclear [24]. Furthermore, we did not find any association with cIMT and sedimentation rate or C-reactive protein. However, these 
Table 2 Other clinical chemistry and clinical biomarkers related to carotid intima-media thickness (cIMT) $\geq 1 \mathrm{~mm}$ as outcome variable

\begin{tabular}{|c|c|c|c|c|}
\hline & $n$ of samples & $\begin{array}{l}\text { cIMT }<1 \mathrm{~mm} \\
\text { mean value } \\
( \pm \mathrm{SD})\end{array}$ & $\begin{array}{l}\mathrm{cIMT} \geq 1 \mathrm{~mm} \\
\text { mean value } \\
( \pm \mathrm{SD})\end{array}$ & $p$ value \\
\hline \multicolumn{5}{|c|}{ Data from first follow-up, 6 years after the index stroke } \\
\hline Chlamydia pneumoniae antibodies & 140 & 3 & 8 & 0.728 \\
\hline Homocysteine $(\mu \mathrm{M})$ & 139 & $12.8(16.7)$ & $11.4 *(7.7)$ & 0.011 \\
\hline CRP (mg/L) & 134 & $2.1(3.1)$ & $2.5(6.5)$ & 0.344 \\
\hline Total cholesterol (mM) & 139 & $5.5(1.1)$ & $6.1 *(1.1)$ & 0.007 \\
\hline LDL cholesterol (mM) & 139 & $3.48(0.9)$ & $3.90 *(1.0)$ & 0.030 \\
\hline HDL cholesterol (mM) & 139 & $1.33(0.4)$ & $1.29(0.4)$ & 0.778 \\
\hline \multicolumn{5}{|c|}{ Data from second follow-up, 12 years after the index stroke } \\
\hline $\mathrm{CRP}(\mathrm{mg} / \mathrm{L})$ & 139 & $2.6(3.0)$ & $3.7(5.7)$ & 0.344 \\
\hline Sedimentation rate (mm) & 135 & $8.8(6.3)$ & $12.9(10.1)$ & 0.055 \\
\hline Homocysteine $(\mu \mathrm{M})$ & 132 & $11.8(10.4)$ & $12.4(7.5)$ & 0.098 \\
\hline Total cholesterol (mM) & 139 & $5.37(1.0)$ & $5.47(1.2)$ & 0.590 \\
\hline LDL-cholesterol (mM) & 138 & $3.41(0.9)$ & $3.54(1.1)$ & 0.543 \\
\hline HDL-cholesterol (mM) & 140 & $1.64(0.5)$ & $1.51(0.4)$ & 0.331 \\
\hline Triglycerides (mM) & 137 & $1.43(0.6)$ & $1.75(0.8)$ & 0.065 \\
\hline Haemoglobin (g/dL) & 139 & $14.0(1.1)$ & $14.6 *(1.3)$ & 0.024 \\
\hline Glycolysed haemoglobin (\%) & 135 & $5.4(0.7)$ & $5.8 *(0.9)$ & $<0.001$ \\
\hline Creatinine $(\mu \mathrm{M})$ & 138 & $64.3(13.6)$ & $83.1 *(70.7)$ & $<0.001$ \\
\hline Leukocytes $\left(10^{9} / \mathrm{L}\right)$ & 140 & $7.3(2.2)$ & $7.2(1.9)$ & 0.948 \\
\hline Thrombocytes $\left(10^{9} / \mathrm{L}\right)$ & 138 & $268(55.4)$ & $262(74.6)$ & 0.221 \\
\hline \multicolumn{5}{|l|}{ Other variables at second follow-up } \\
\hline Age (years) & 140 & $45.6(9.9)$ & $55.2 *(5.8)$ & $<0.001$ \\
\hline Gender & & & $*$ & 0.001 \\
\hline Males $(N)$ & & 10 & 68 & \\
\hline Females $(N)$ & & 24 & 38 & \\
\hline Blood pressure (mmHg) & 137 & & & \\
\hline Systolic & & $131(18.4)$ & $143 *(16.8)$ & 0.001 \\
\hline Diastolic & & $84(11.1)$ & $90 *(9.9)$ & 0.002 \\
\hline$n$ of smoking years & 53 active and 54 ex-smokers & $22.3(10.0)$ & $26.9(10.2)$ & 0.078 \\
\hline AAE & & 6 & $46^{*}$ & 0.008 \\
\hline
\end{tabular}

$3 \times 2$ chi-square test and Fisher's exact test for categorical variables and Wilcoxon-Mann-Whitney test for continuous variables were used for comparison of data. Mean value $( \pm \mathrm{SD})$

$n$ number, $S D$ standard deviation, $\mu M$ micromole, $C R P$ C-reactive protein, $L D L$ low density lipoprotein, $H D L$ high density lipoprotein, $A A E$ additional arterial event other than the index stroke (recurrent ischemic stroke, angina pectoris, myocardial infarction, peripheral artery disease)

parameters are crude markers for the evaluation of specific immune responses in the vascular wall.

We also studied the Fc $\gamma \mathrm{R}$ and IL10 genotypes as they have been linked to atherosclerosis. The frequencies of the Fc $\gamma \mathrm{R}$ and IL-10 genotypes among our patients were comparable to 272 healthy controls previously reported from western Norway $[25,26]$.

We found a significant association between Fc $\gamma$ RIIIB $\mathrm{NaII} / \mathrm{NaII}$ and cIMT $\geq 1 \mathrm{~mm}$. However, linear regression analysis showed non-significant results for continuous maximum cIMT values. Others have reported that soluble Fc $\gamma$ RIIIA is associated with maximum cIMT [27], that the Fc $\gamma$ RIIIA VV- genotype is inversely related to the extent of coronary artery disease [6] and that the FcyRIIA R allele is associated with impaired endothelial vasodilation in patients with hypercholesterolemia [28].

The present study is the first to show a possible association with the low-affinity Fc $\gamma$ RIIIB receptor and atherosclerosis as measured by cIMT $\geq 1 \mathrm{~mm}$. Fc $\gamma$ RIIIB, as well as Fc $\gamma$ RIIA and Fc $\gamma$ RIIIA, activates immune functions such as phagocytosis, ADCC and release of inflammatory mediators and superoxide radicals [29]. Fc $\gamma$ RIIIB is only present on granulocytes, and the Fc $\gamma$ RIIIB-NA2 allotype shows lower levels of phagocytosis of IgG1 and IgG3 opsonised particles 
Table 3 Significant results of unadjusted logistic regression and adjusted backward stepwise logistic regression analysis, related to maximum carotid intima-media thickness, categorised as $<1$ and $\geq 1 \mathrm{~mm}$ in 140 patients, measured 12 years after acute ischemic stroke

\begin{tabular}{|c|c|c|c|c|c|c|}
\hline \multirow[b]{2}{*}{ Variables } & \multicolumn{3}{|c|}{ Unadjusted logistic regression } & \multicolumn{3}{|c|}{ Adjusted logistic regression } \\
\hline & OR & $(95 \% \mathrm{CI})$ & $p$ values & OR & $(95 \% \mathrm{CI})$ & $p$ values \\
\hline $\mathrm{Fc} \gamma \mathrm{RIIIB} \mathrm{NaI/NaI}$ & 1.00 & & & & & \\
\hline Fc $\gamma$ RIIIB NaII/NaII & 2.78 & $1.18,6.52$ & 0.019 & 3.94 & $1.08,14.3$ & 0.037 \\
\hline Cholesterol & 1.62 & $1.12,2.34$ & 0.010 & - & - & - \\
\hline SR & 1.06 & $1.01,1.12$ & 0.031 & - & - & - \\
\hline $\mathrm{Hb}$ & 1.41 & $1.02,1.95$ & 0.036 & - & - & - \\
\hline $\mathrm{HbAlc}$ & 3.35 & $1.27,8.86$ & 0.015 & 6.65 & $1.21,36.5$ & 0.029 \\
\hline Triglycerides & 1.75 & $1.00,3.07$ & 0.049 & - & - & - \\
\hline Creatinine & 1.05 & $1.02,1.08$ & 0.001 & - & - & - \\
\hline Age & 1.17 & $1.10,1.25$ & $<0.001$ & 1.13 & $1.04,1.23$ & 0.003 \\
\hline Male gender & 4.30 & $1.86,9.93$ & 0.001 & 4.07 & $1.15,14.5$ & 0.030 \\
\hline Systolic BP & 1.05 & $1.02,1.08$ & 0.002 & - & - & - \\
\hline Diastolic BP & 1.06 & $1.01,1.10$ & 0.008 & - & - & - \\
\hline AAE & 3.64 & $1.39,9.53$ & 0.009 & - & - & - \\
\hline
\end{tabular}

Unadjusted univariate logistic regression analysis was performed for all blood samples from the first and second follow-up: Fc $\gamma \mathrm{R}$ polymorphisms, IL-10 polymorphisms, Chlamydia pneumoniae antibodies, homocysteine, Creactive protein, total cholesterol, LDL cholesterol, HDL cholesterol, SR, triglycerides, Hb, HbAlc, creatinine, leukocytes and thrombocytes and for clinical variables, such as age, gender, systolic BP, diastolic BP and AAE. Only significant found variables are listed and used in the adjusted backward stepwise logistic regression analysis $O R$ odds ratio, $C I$ confidence interval, $F c \gamma R$ Fc gamma receptor polymorphism, $S R$ sedimentation rate, $H b$ haemoglobin, $H b A l c$ glycolysed haemoglobin, $B P$ blood pressure, $A A E$ additional arterial events (recurrent stroke and/or angina pectoris and/or myocardial infarction and/or peripheral artery disease) other than the index stroke than the NA1 allotype [30]. Our results therefore indicate that reductions in effector functions such as phagocytosis and ADCC may contribute to the development of atherosclerosis. Such findings are supported by knockout studies of the inhibitory Fc $\gamma$ RIIB which shows an increased plaque formation [31]. In addition to myeloid cells, Fc $\gamma$ RIIB is expressed on B cells where it suppresses B cell signaling and regulates $\operatorname{IgG}$

Table 4 Final results of linear regression analysis, related to maximum carotid intima-media thickness (cIMT), measured in 140 patients 12 years after acute ischemic stroke

\begin{tabular}{llll}
\hline & $\mathrm{b}$ & Standard error (SE) & $p$ values \\
\hline Age & 0.25 & 0.007 & 0.002 \\
Systolic BP & 0.18 & 0.003 & 0.029 \\
AAE & 0.20 & 0.111 & 0.019 \\
HbA1c & 0.18 & 0.061 & 0.028 \\
\hline
\end{tabular}

Linear regression analysis was performed with Fc gamma receptor IIIB $\mathrm{NaII} / \mathrm{NaII}$ polymorphism, total cholesterol, sedimentation rate, haemoglobin, HbA1c, triglycerides, creatinine, age, gender, systolic BP and AAE. Gender was non-significant in the final results $(b=0.13, \mathrm{SE}=$ $0.1, p=0.80)$

$b$ estimated regression coefficient, $B P$ blood pressure, $A A E$ additional arterial event other than the index stroke, such as recurrent ischemic stroke, angina pectoris, myocardial infarction and peripheral artery disease, $H b A 1 c$ glycolysed haemoglobin production [32]. Defects of Fc $\gamma$ RIIB on B cell will therefore increase the $\mathrm{IgG}$ production, which was showed in this mouse model [31]. Our results indicate that similar mechanisms may take place in humans, as the NA2 allotype is associated with reduced phagocytosis of $\operatorname{IgG} 1$ and $\operatorname{IgG} 3$ [30].

Stimulation of activating Fc $\gamma$ Rs on macrophages has been found to induce an anti-inflammatory immune response with increased IL-10 production [15]. It has also been proposed that elevated IgG with IL-10 acting downstream is driving the plaque formation [31]. Others have reported that reduced levels of IL-10 and low-producing IL-10 genotypes are associated with increased cIMT $[10,33]$ and that low-producing IL-10 genotypes are associated with coronary disease [11] and ischemic stroke [34].

We have also studied the polymorphisms of IL-10 since $50-70 \%$ of the variance in IL-10 levels is genetically determined [35]. However, we found no association between high-, medium- or low-producing IL-10 genotypes and cIMT $\geq 1 \mathrm{~mm}$. Unfortunately, we had no access to serum IL-10 levels in our patients. Although we could not find any genetic risk factor with IL-10 and cIMT, this does not exclude the importance of this anti-inflammatory cytokine in the pathogenesis of atherosclerosis. The major roles of IL-10 in terms of atherosclerosis include inhibition of macrophage activation, as well as inhibition of matrix metalloproteinase, pro-inflammatory cytokines and cyclooxygenase-2 expression in lipid-loaded 
and activated macrophage foam cells. Furthermore, another important role of IL-10 in atherosclerosis is its ability to alter lipid metabolism in macrophages [36]. Of the nonimmunological parameters, we found that cholesterol, triglycerides, blood pressure and cardiovascular events were risk factors in the unadjusted logistic regression analysis but not in the adjusted logistic regression analysis. However, these are known risk factors for subclinical carotid atherosclerosis [37, 38] At the first follow-up, statins were only used by 30 $(15.5 \%)$ of 194 patients with registered medication, and at the second follow-up, statins were used by 55 (38.2\%) of 144 patients [16]. The increasing use of statins probably explains why total cholesterol/homocysteine/and LDL-cholesterol levels were associated with cIMT at the first follow-up but not at the second follow-up.

We found that $\mathrm{HbA1c}, \mathrm{SR}$, haemoglobin and creatinine were risk factors in the unadjusted logistic regression analysis, but only $\mathrm{HbA} 1 \mathrm{c}$ showed significance in the final adjusted logistic and linear regression analysis. Elevated blood glucose is a known risk factor for endothelial dysfunction and early atherosclerosis [39], and the high percentage of carotid artery atherosclerosis observed in our patients is in agreement with this. Furthermore, we found that increased age and male gender are correlated with increased cIMT as has been shown in large population studies [37, 40]. Surprisingly, male gender disappeared as significant result in the linear regression analysis, and other risk factors for increased cIMT and atherosclerosis, such as systolic BP and additional arterial events, became significant. Probably, the number of patients played a role for the varying results by the different methods of regression analysis.

The strength of our study is that we have a very well characterised patient population and clinically related immunological and non-immunological parameters were available for analysis. The frequencies of Fc $\gamma \mathrm{R}$ and IL-10 polymorphisms in our patients are similar to those observed in population studies performed from the same area [25, 26]. We have measurements of the various blood samples both at first and at second follow-up. In addition, we did meticulous studies to measure cIMT and plaques.

The weakness of our study is that patients were included retrospectively and selection was affected by death and a $23 \%$ dropout rate of long-term survivors. The $23 \%$ dropout rate at our last clinical follow-up, without any missing data concerning the dead-alive status, is, however, comparable to that of other clinical studies with follow-ups after 10 years [41].

Differences occurred after logistic and linear regression analysis concerning significancies related to cIMT in this study. However, age and $\mathrm{HbA1c}$ were in both analyses related to cIMT, and these parameters are well-known risk factors for increased cIMT and atherosclerosis. Male gender and increased $\mathrm{BP}$ are also well-known risk factors for atherosclerosis and additional arterial events, even if the results by the two types of regression analysis were slightly different. A new finding in this study is that Fc $\gamma$ RIIIB-NAII/NAII appeared as a significant factor for increased cIMT $\geq 1 \mathrm{~mm}$. However, further prospective studies with higher sample sizes are necessary to confirm these results.

In conclusion, we found that in patients with ischemic stroke at a young age, Fc $\gamma$ RIIIB-NAII/NAII may be a contributing factor for increased cIMT together with known risk factors, such as age, male gender, systolic BP and increased HbA1c.

Acknowledgments We thank Terje Ertkjern and co-workers from the laboratory of clinical biochemical medicine for the analysis of routine blood samples.

Conflict of interest Ulrike Waje-Andreassen, Halvor Naess, Lars Thomassen, Tove Helene Maroy, Kibret Yimer Mazengia, Geir Egil Eide and Christian Alexander Vedeler declare that they have no conflicts of interest concerning this study.

Ethical approval The study procedures were in accordance with the Helsinki Declaration of 1975. The Western Norway Regional Committee for Medical Research Ethics approved the study (project ID: 82.04); The Norwegian Royal Department of Health approved the research biobank, connected to the project (ID number: 200403628). Informed consent was obtained from all patients for being included in the study. Investigators were not allowed to ask patients about reasons for non-participation during the first and second follow-up.

Open Access This article is distributed under the terms of the Creative Commons Attribution 4.0 International License (http:// creativecommons.org/licenses/by/4.0/), which permits unrestricted use, distribution, and reproduction in any medium, provided you give appropriate credit to the original author(s) and the source, provide a link to the Creative Commons license, and indicate if changes were made.

\section{References}

1. Wang X, Liu X, Kishimoto C, Yuan Z. The role of fcgamma receptors in atherosclerosis. Exp Biol Med (Maywood). 2012;237(6): 609-16.

2. Raaz D, Herrmann M, Ekici AB, Klinghammer L, Lausen B, Voll RE, et al. FcgammaRIIa genotype is associated with acute coronary syndromes as first manifestation of coronary artery disease. Atherosclerosis. 2009;205(2):512-6.

3. Kim YS, Yoo JH, Lee BC. Susceptibility for ischemic stroke in Korean population is associated with polymorphisms of the $\mathrm{Fc}$ gamma receptor IIA. Blood Coagul Fibrinolysis. 2009;20(5):3537.

4. Karakas M, Hoffmann MM, Vollmert C, Rothenbacher D, Meisinger C, Winkelmann B, et al. Genetic variation in Fc gamma receptor IIa and risk of coronary heart disease: negative results from two large independent populations. BMC medical genetics 2009;1046

5. van der Meer IM, Witteman JC, Hofman A, Kluft C, de Maat MP. Genetic variation in fcgamma receptor IIa protects against advanced peripheral atherosclerosis. The Rotterdam Study Thromb Haemost. 2004;92(6):1273-6. 
6. Gavasso S, Nygard O, Pedersen ER, Aarseth JH, Bleie O, Myhr $\mathrm{KM}$, et al. Fcgamma receptor IIIA polymorphism as a risk-factor for coronary artery disease. Atherosclerosis. 2005;180(2):277-82.

7. Bjorkbacka H, Fredrikson GN, Nilsson J. Emerging biomarkers and intervention targets for immune-modulation of atherosclerosis - a review of the experimental evidence. Atherosclerosis. 2013;227(1):9-17.

8. Caligiuri G, Rudling M, Ollivier V, Jacob MP, Michel JB, Hansson $\mathrm{GK}$, et al. Interleukin-10 deficiency increases atherosclerosis, thrombosis, and low-density lipoproteins in apolipoprotein E knockout mice. Mol Med. 2003;9(1-2):10-7.

9. Sikka G, Miller KL, Steppan J, Pandey D, Jung SM, Fraser 3rd CD, et al. Interleukin 10 knockout frail mice develop cardiac and vascular dysfunction with increased age. Exp Gerontol. 2013;48(2): 128-35.

10. Ambrosius W, Kazmierski R, Michalak S, Kozubski W. Antiinflammatory cytokines in subclinical carotid atherosclerosis. Neurology. 2006;66(12):1946-8.

11. George J, Schwartzenberg S, Medvedovsky D, Jonas M, Charach $\mathrm{G}$, Afek A, et al. Regulatory T cells and IL-10 levels are reduced in patients with vulnerable coronary plaques. Atherosclerosis. 2012;222(2):519-23.

12. Eskdale J, Gallagher G, Verweij CL, Keijsers V, Westendorp RG, Huizinga TW. Interleukin 10 secretion in relation to human IL-10 locus haplotypes. Proc Natl Acad Sci U S A. 1998;95(16):9465-70.

13. Crawley E, Isenberg D, Woo P, Kay R. Interleukin-10 promoter polymorphism and lupus nephritis: comment on the article by Mok et al. Arthritis Rheum. 1999;42(3):590-3.

14. Turner DM, Williams DM, Sankaran D, Lazarus M, Sinnott PJ, Hutchinson IV. An investigation of polymorphism in the interleukin-10 gene promoter. Eur J Immunogenet. 1997;24(1):1-8.

15. Gallo P, Goncalves R, Mosser DM. The influence of IgG density and macrophage Fc (gamma) receptor cross-linking on phagocytosis and IL-10 production. Immunol Lett. 2010;133(2):70-7.

16. Waje-Andreassen U, Thomassen L, Jusufovic M, Power KN, Eide $\mathrm{GE}$, Vedeler CA, et al. Ischaemic stroke at a young age is a serious event - final results of a population-based long-term follow-up in Western Norway. Eur J Neurol. 2013;20(5):818-23.

17. Waje-Andreassen U, Naess H, Thomassen L, Eide GE, Meijer R, Vedeler CA. Ultrasound, atherosclerosis and stroke at a young age: a cross-sectional long-term follow-up in western Norway. Eur J Neurol 2008;15512-9

18. Johnson CJ, Kittner SJ, McCarter RJ, Sloan MA, Stern BJ, Buchholz D, et al. Interrater reliability of an etiologic classification of ischemic stroke. Stroke. 1995;26(1):46-51.

19. Naess H, Nyland HI, Thomassen L, Aarseth J, Nyland G, Myhr $\mathrm{KM}$. Incidence and short-term outcome of cerebral infarction in young adults in western Norway. Stroke. 2002;33(8):2105-8.

20. Waje-Andreassen U, Naess H, Thomassen L, Eide GE, Vedeler CA. Long-term mortality among young ischemic stroke patients in western Norway. Acta Neurol Scand. 2007;116(3):150-6.

21. Myhr KM, Vagnes KS, Maroy TH, Aarseth JH, Nyland HI, Vedeler CA. Interleukin-10 promoter polymorphisms in patients with multiple sclerosis. J Neurol Sci. 2002;202(1-2):93-7.

22. Temelkova-Kurktschiev T, Fischer S, Koehler C, Mennicken G, Henkel E, Hanefeld M. Intima-media thickness in healthy probands without risk factors for arteriosclerosis. Dtsch Med Wochenschr. 2001;126(8):193-7.

23. Aminbakhsh A, Mancini G. Carotid intima-media thickness measurements: what defines an abnormality? a systematic review. Clin Invest Med. 1999;22(4):149-57.

24. Joshi R, Khandelwal B, Joshi D, Gupta OP. Chlamydophila pneumoniae infection and cardiovascular disease. N Am J Med Sci. 2013;5(3):169-81.
25. Torkildsen O, Utsi E, Mellgren SI, Harbo HF, Vedeler CA, Myhr $\mathrm{KM}$. Ethnic variation of Fc gamma receptor polymorphism in Sami and Norwegian populations. Immunology. 2005;115(3):416-21.

26. Torkildsen O, Utsi E, Harbo HF, Mellgren SI, Vedeler CA, Myhr KM. Ethnic variations of IL-10 polymorphisms in a Sami and Norwegian population. Scand J Immunol. 2005;62(1):71-4.

27. Masuda M, Amano K, Hong SY, Nishimura N, Fukui M, Yoshika $\mathrm{M}$, et al. Soluble FcgammaRIIIa (Mphi) levels in plasma correlate with carotid maximum intima-media thickness (IMT) in subjects undergoing an annual medical checkup. Mol Med. 2008;14(7-8): 436-42.

28. Schneider MP, Leusen JH, Herrmann M, Garlichs CD, Amann K, John S, et al. The Fcgamma receptor IIA R131H gene polymorphism is associated with endothelial function in patients with hypercholesterolaemia. Atherosclerosis. 2011;218(2):411-5.

29. Guilliams M, Bruhns P, Saeys Y, Hammad H, Lambrecht BN. The function of Fcgamma receptors in dendritic cells and macrophages. Nat Rev Immunol. 2014;14(2):94-108.

30. van der Pol W, van de Winkel JG. IgG receptor polymorphisms: risk factors for disease. Immunogenetics. 1998;48(3):222-32.

31. Harmon EY, Fronhofer 3rd V, Keller RS, Feustel PJ, Zhu X, Xu H, et al. Anti-inflammatory immune skewing is atheroprotective: apoe -/-FcgammaRIIb-/- mice develop fibrous carotid plaques. J Am Heart Assoc. 2014;3(6):e001232.

32. Smith KG, Clatworthy MR. FcgammaRIIB in autoimmunity and infection: evolutionary and therapeutic implications. Nat Rev Immunol. 2010;10(5):328-43.

33. Kahraman S, Yilmaz R, Arici M, Altun B, Erdem Y, Yasavul U, et al. IL-10 genotype predicts serum levels of adhesion molecules, inflammation and atherosclerosis in hemodialysis patients. J Nephrol. 2006;19(1):50-6.

34. Xie G, Myint PK, Zaman MJ, Li Y, Zhao L, Shi P, et al. Relationship of serum interleukin-10 and its genetic variations with ischemic stroke in a Chinese general population. PLoS One. 2013;8(9):e74126.

35. de Craen AJ, Posthuma D, Remarque EJ, van den Biggelaar AH, Westendorp RG, Boomsma DI. Heritability estimates of innate immunity: an extended twin study. Genes Immun. 2005;6(2):167-70.

36. Han X, Boisvert WA. Interleukin-10 protects against atherosclerosis by modulating multiple atherogenic macrophage function. Thromb Haemost. 2015;113(3):505-12.

37. Stensland-Bugge E, Bonaa KH, Joakimsen O. Age and sex differences in the relationship between inherited and lifestyle risk factors and subclinical carotid atherosclerosis: the tromso study. Atherosclerosis. 2001;154(2):437-48.

38. Davis PH, Dawson JD, Riley WA, Lauer RM. Carotid intimalmedial thickness is related to cardiovascular risk factors measured from childhood through middle age: the Muscatine study. Circulation. 2001;104(23):2815-9.

39. Sinning C, Kieback A, Wild PS, Schnabel RB, Ojeda F, Appelbaum $\mathrm{S}$, et al. Association of multiple biomarkers and classical risk factors with early carotid atherosclerosis: results from the Gutenberg Health Study. Clinical research in cardiology : official journal of the German Cardiac Society 2014.

40. Lorenz MW, Markus HS, Bots ML, Rosvall M, Sitzer M. Prediction of clinical cardiovascular events with carotid intima-media thickness: a systematic review and meta-analysis. Circulation. 2007;115(4):459-67.

41. Gustavson K, von Soest T, Karevold E, Roysamb E. Attrition and generalizability in longitudinal studies: findings from a 15 -year population-based study and a Monte Carlo simulation study. BMC Public Health 2012;12918 